the Diplomatic Conference. Then, in five working groups, participants considered how Societies could disseminate knowledge of the Geneva Conventions among the population. They also attended the showing of the film " Red Cross on a white field".

The League delegates lectured on the way ideas about the Red Cross had evolved internationally and they directed work and discussions on subjects on the agenda: health education-relieffinance and management-fund raising-blood transfusion-past development of the Red Cross in Africa-the role of the voluntary worker.

All displayed keen interest in the instruction received; they realized the importance of Red Cross activities, particularly the dissemination of humanitarian law principles, which constituted a factor for peace in the world. In addition, they studied administration and public relations methods which would be useful to them in the discharge of the responsibilities they shoulder in their own countries under the sign of the red cross.

\title{
ANNUAL REPORT OF THE LEAGUE
}

The 1972 Annual Report of the League of Red Cross Societies, with fifty-two pages and many illustrations, contains information under the following headings: Conclusions of the Executive Committee, General activities, Relief, Disaster relief preparedness, Health, Social Welfare, Nursing, Youth, Information, International relations, Administration and Personnel, and Financial situation.

In the Introduction, Mr. Henrik Beer, Secretary General of the League, refers to the institution's undertakings and achievements in various fields in the course of the year. He appraises the "less 


\section{IN THE RED CROSS WorLd}

satisfactory aspects " due to limited resources for ever-increasing tasks, but he also stresses the outstanding work of organizing and running seminars and training institutes to help many National Societies to shoulder their responsibilities more fully and effectively. He also draws attention to the emergencies with which the League has had to cope.

“... With regard to the special effort made by the Secretariat in training personnel, mention should be made of the importance of the work required in the organization of Training Institutes and technical seminars. This is a great challenge, as nothing less is involved than to increase the efficiency of the organization, to work in a more constructive way, and to give added impetus to the common efforts of working groups. These are all decisive factors in human development, which is another major activity of the Red Cross.

At the same time Red Cross solidarity has rarely been put to the test to such an extent. In 1972 the League had to cope with 20 emergency situations in 16 countries, in particular in Bangladesh where the situation of thousands of people made it necessary to mobilize the members of the Federation while continuing its action for displaced persons and refugees in war-torn countries, on the Asian continent in particular.

These actions once again showed the overriding necessity of National Societies-in particular those in the disaster beltmaking adequate preparations for disasters, establishing relief plans and having qualified personnel for relief actions "... 